\title{
INSURGENCE OF MAGGOTS AROUND COLOSTOMY: AN UNUSUAL PRESENTATION
}

Rajiv Jain¹, Vikrant Ranjan², Ravi Dosi³

1. Assistant Professor, Department of Surgery, Sri Aurobindo Medical College and Post-Graduate institute Indore.

2. Resident, Department of Surgery, Sri Aurobindo Medical College and Post-Graduate institute Indore.

3. Assistant Professor, Department of Pulmonary Medicine, Sri Aurobindo Medical College and Post-Graduate institute Indore.

\section{CORRESPONDING AUTHOR:}

Dr. Rajiv Jain, 626, Sneh Nagar,Flat No 101, Gautamshri Apartment, Indore. Madhya Pradesh- 452001.

Email-drrajivjain16@yahoo.com

ABSTRACT: Insurgence of Maggot's is an uncommon feature of colostomy site. Maggots' infestation has been reported over sites like nose, ear, orbit, tracheotomy wound, face, gums and serous cavities. We report a case of maggots infestation surrounding the colostomy site, which to the best of our knowledge, is the first reported case in the review of the literature. A patient of advanced inoperable adenocarcinoma rectum presented with complaints of constant vague pain, discomfort and foul smelling discharge over colostomy site. On exploration, maggots were identified as the cause and patient was relieved of his agony by their meticulous eradication. We emphasize that Stoma Care should be constantly monitored to prevent Maggot infestation and prevention counseling should be included in the stoma care protocol in tropical countries.

KEYWORDS: colostomy; myiasis; maggots; stoma care.

INTRODUCTION: Living with a stoma is a challenge. In advanced inoperable rectal carcinoma cases, permanent colostomy is frequently required. The patients with stoma may develop complication like parastomal hernia, stomal stenosis, necrosis, retraction, skin irritation or rare complications like prolapse, perforation, fistula, dehydration etc. [10]. Colostomy care is a very important domain of the post operative care but it is sometimes neglected by the patient and relatives in developing countries. Maggot's infestation was not considered as a colostomy site complication as stoma is covered by colostomy bag and clothes, while maggot's infestation usually occurs over exposed areas.

Myiasis, the infestation of live human and vertebrate animals with dipterous fly maggots is common throughout the tropical region [1]. Infestation with maggots causes severe pain and mental agony among humans, while hammering economic loss significantly among domestic mammals [2]. Despite the fact that the scourge is very common in rural areas of the tropical region, myiasis has been reported around the world [3], [4], [5]. Severity of myiasis depends on the location of the infestation, lesions and tissue inflammation. Myiasis can cause massive destruction in neglected patients accompanied by marked inflammatory reactions and secondary bacterial infections. 
We report an unusual case of an Indian male with colostomy in situ presenting with complaints of parastomal skin irritation, foul smelling discharge and constant vague pain around stoma site, the cause of which was found to be maggot infestation.

CASE REPORT: A 45-year-old non diabetic Indian male was admitted in the department of surgery for colostomy related problems. In a different tertiary care hospital, sigmoid loop colostomy was done for an inoperable carcinoma rectum about three month ago and he was thriving well at home with stoma in situ. He presented with constant vague pain, foul smelling discharge, skin irritation and abnormal sensation(of something crawling)at colostomy site. On general examination, vitals were stable with no fever, edema, icterus or lymphadenopathy .Mild pallor was present and his nutritional level and personal hygiene was low. He looked anxious and psychologically distressed. Systemic examination of other systems did not reveal any abnormality. On palpation, the abdomen was soft, with no palpable abnormality except mild hepatomegaly. He had a sigmoid loop colostomy in the left iliac region. Per rectal digital examination was suggestive of a hard circumferential ulceroproliferative growth in the lower rectum which bled slightly on touch.

Local examination revealed functioning colostomy with healthy mucosa. The parastomal skin and subcutaneous tissues were inflamed. There were multiple burrows and thick whitish flakes of pus in the skin surrounding the colostomy. On gentle exploration of burrows with artery forceps, numerous creeping maggots were found (Fig. 1).

The hematological profile revealed anemia, leucocytosis with raised lymphocyte count and increased ESR. The biochemical and serological tests were normal. The patient was managed conservatively with systemic antibiotics and the proper stoma care. The maggot infestation was managed by application of turpentine oil as repellent for maggots followed by gentle removal by instruments (Fig. 2). All maggots could be removed in 2-3 days with no fresh crop of maggots. Simultaneously his nutritional rehabilitation was initiated.

Patient was discharged after a week in a healthy condition with a well functioning maggot free stoma .An advice regarding proper colostomy care and palliative treatment for his advanced malignancy of rectum was given on discharge.

DISCUSSION AND REVIEW OF LITERATURE: Myiasis is a term derived from the Greek word "myia", meaning invasion of vital tissue of humans or other mammals by fly larvae [11-15]. Myiasis was defined by Zumpt as the infestation of live human and vertebrate animals by dipterous larva, which at least for a certain period feed on host's dead or living tissue, liquid body substances or ingested food [16]. Although female flies are attracted to odoriferous suppurating lesions and open wounds, the eggs are deposited on the unbroken, soft skin of various parts of the body that are contaminated by blood or mucous discharge. In addition, the eggs can be transferred into these sites by patient's own fingers due to poor hygienic habits.

Before the occurrence of major functional disturbance associated with extension of the lesion, signs of infestation include presence of ragged, foul smelling lesion containing the maggots. Extension of lesion into body cavity would be seen in some of the cases[6], here the patient experienced pain/discomfort as early feature, though it becomes painless when the larvae destroys the sensory nerve endings during the process of invasion. The pathogenicity results from inflammation and toxin secreted by the larvae which prevents healing [4]. 
Infestation is common in tropical countries, especially India (3), (7). Genitourinary myiasis in man has been reported to be associated with poor general health and hygiene, restricted mobility, urinary obstruction and ulcerating lesions [2] .However, genitourinary involvement is rare with only one documented case from India [8]. The sites commonly involved in myiasis are nose, ear, tracheotomy wound, orbit and eye, face, gums and serous cavities [4]. We did not come across any case of maggots' infestation at the colostomy site in review of literature.

In the treatment of such patients, general supportive measures like improving the nutrition, correction of anemia, psychological support and attention to local hygiene are helpful. Proper methods for the treatment of wound myiasis are not well defined [17, 19]. Various authors have described Occlusion/suffocation approaches in which the occluding materials like turpentine oil, petroleum jelly, liquid paraffin, beeswax or heavy oil, or lard or bacon strips are placed over the central punctum and have been used to coax the larva to emerge spontaneously head-first, which are captured by tweezers (or forceps).[17,18]The treatment is simple and involves usage of antilarval measures (turpentine oil or mixture of turpentine oil and chloroform) followed by removal of the larvae [9]. Surgical excision may be used if the larva is dead or if other methods have failed. In any case, care should be taken not to rupture the maggots because they may cause secondary infections or trigger potentially severe allergic reactions [17]. A broad antibiotic cover is recommended to prevent secondary infections [19].

Our case illustrate the importance of hygiene and sanitation in tropical countries with high fly population and emphasize the need for better counseling regarding stoma care and about prompt diagnosis of myiasis, which could be potentially dangerous if left untreated. Though maggots insurgence is not considered to be a threat to colostomy site but in view of tropical country like India where the flies population is rampant it is wiser to include its counseling in stoma care and the clinician should consider it as one of the possible differential diagnosis particularly in a case of colostomy presenting with local pain and discomfort. Through proper health care the maggot's insurgence and its consequences can be avoided.

CONCLUSION: Though maggots insurgence is not considered to be a threat to colostomy site but in view of tropical country like India where the flies population is rampant it is wiser to include its counseling in stoma care and the clinician should consider it as one of the possible differential diagnosis particularly in a case of colostomy presenting with local pain and discomfort. Through proper health care the maggot's insurgence and its consequences can be avoided.

\section{REFERENCES}

1. Shivekar S, Senthil K, Srinivasan R, Sureshbabu L, Chand P, Shanmugam J, Gopal R. Intestinal myiasis caused by Muscina stabulans. Indian J Med Microbiol 2008;26:83-5

2. Spradbery JP. A manual for the diagnosis of screw-worm fly: Commonwealth Scientific and Industrial Research Organization, Division of Entomology; Canberra, Australia; 1991. p. 162.

3. Verma L, Pakrasi S, Kumar A, Sachdev MS, Mandal AK. External opthalmomyiasis associated with herpes zoster opthalmicus. Can J Opthalmol 1990; 25:42-3.

4. Kersten RC, Shoukrey NM, Tabara KF. Orbital myiasis. Opthalmology 1986; 93:1228-32. 
5. Wadhwa V, Kharbanda P, Rai S, Uppal B. Urogenital myiasis due to Chrysomyia bezziana. Indian J Med Microbiol 2006; 24:70-1.

6. Gopalakrishnan, S., Srinivasan, R., Saxena, S., \& Shanmugapriya, J. (2008). Myiasis in different types of carcinoma cases in southern India. Indian Journal of Medical Microbiology, 26(2), 189-192.

7. Sachdev MS, Kumar H, Roop, Jain AK, Arora R, Dada VK. Destructive ocular myiasis in a noncompromised host. Indian J Opthalmol 1990; 38:184-6

8. Menon S, Bharadwaj R, Rajput AG, Khare PM, Menon S, Bharadwaj R. Genital myiasis: Chrysomyia bezziana. Indian J Med Microbiol 1996; 14:213-4.

9. Singh I, Gathwala G, Yadav SP, Wig U. Ocular myiasis. Indian Pediatr 1991; 28:1524-5.

10. Mahjoubi B, Moghimi A, Mirzaei R, Bijari A. Evaluation of the end colostomy complications and the risk factors influencing them in Iranian patients. Colorectal Dis. 2005 Nov; 7(6):582-7.)Anil S, Jacob OA, Hari S. Oral myiasis: A case report. Ann Dent. 1989; 48:28-30.

11. Mohammadzadeh T, Hadadzadeh R, Esfandiari F, Sadjjadi SM. A case of gingival myiasis caused by Wohlfahrtia magnifica. Iranian J Arthropod Borne Dis. 2008; 2:53-6.

12. Carvalho RW, Santos TS, Antunes AA, Laureano Filho JR, Anjos ED, Catunda RB. Oral and maxillofacial myiasis associated with epidermoid carcinoma: A case report. J Oral Sci. 2008; 50:103-5.

13. Abdo EN, Sette-Dias AC, Comunian CR, Assis Dutra CE, de Aguiar EG. Oral myiasis: A case report. Med Oral Patol Oral Cir Bucal. 2006; 11:E130-1.

14. Auluck A. Oral health of poor people in rural areas of developing countries. J Can Dent Assoc. 2005; 71:753-5.

15. Shinohara EH, Martini MZ, de Oliveira Neto HG, Takahashi A. Oral myiasis treated with ivermectin: Case report. Braz Dent J. 2004; 15:79-81.

16. Caissie R: Cutaneous myiasis: diagnosis, treatment and prevention. J. Oral. Maxillofac. Surg. 66 560-568, 2008.

17. Boggild AK, Keystone JS, Kain KC: Furuncular myiasis: A simple and rapid method for extraction of intact Dermatobia Hominis larvae. Clin Infect Dis 35:336, 2002

18. Sherman RA: Wound myiasis in urban and suburban United States. Arch. Intern. Med. 160: 2004-2014, 2000 


\section{CASE REPORT}

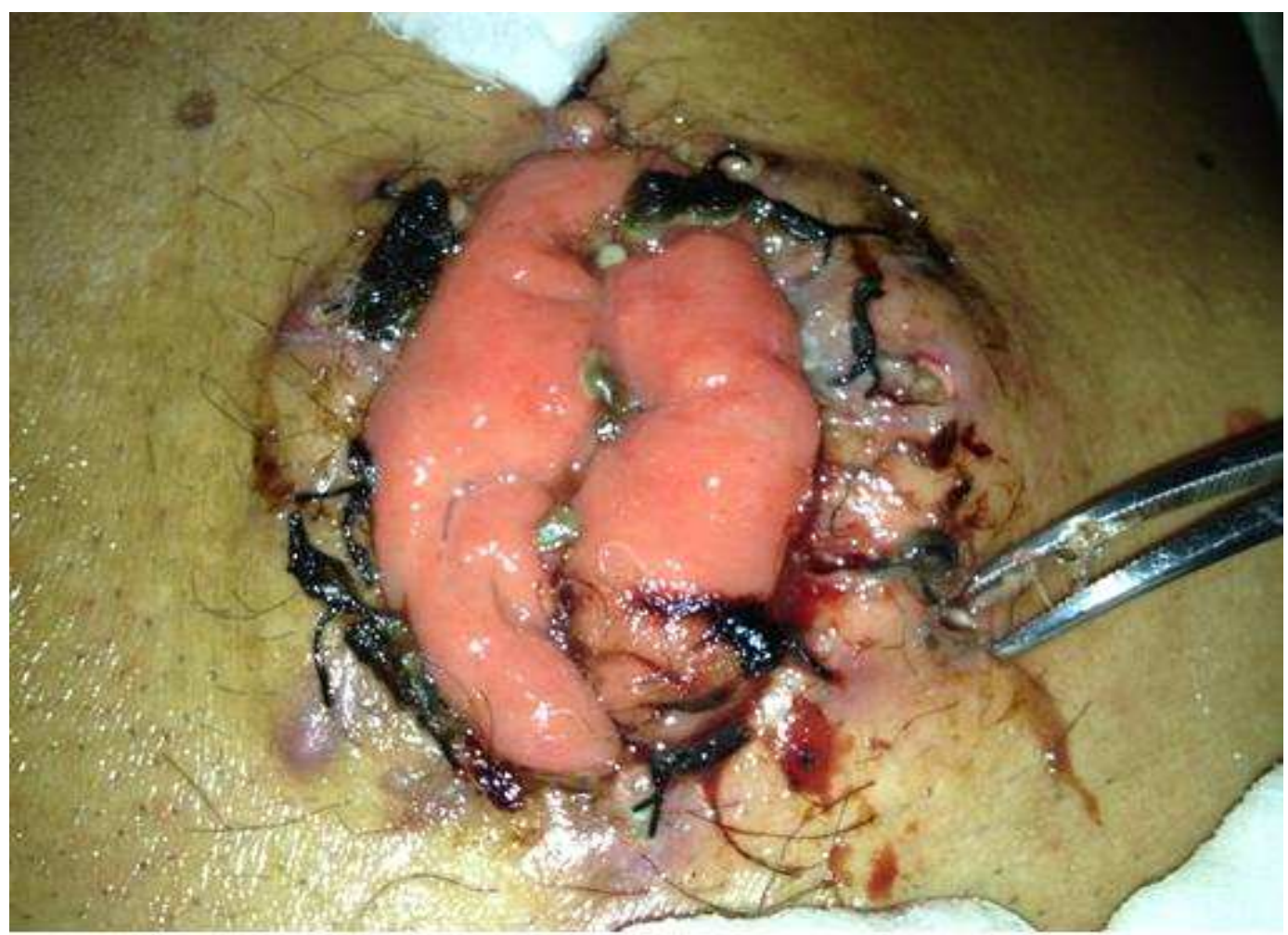

FIGURE 1: Photograph of maggots surrounding the colostomy site

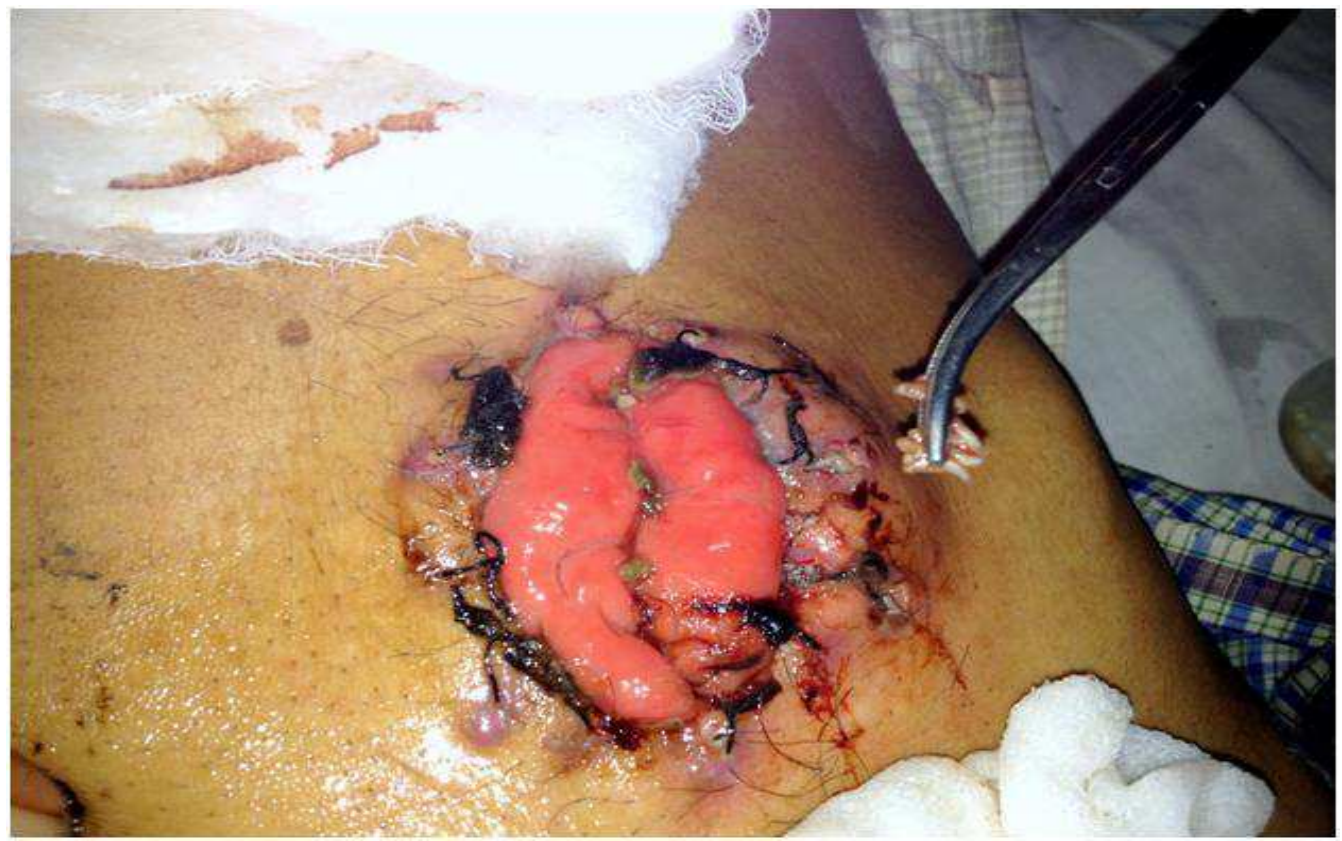

FIGURE 2: Photograph of mechanical removal of maggots with the help of artery forceps. 